\title{
LINKING DIGITAL TECHNOLOGIES AND DYNAMIC CAPABILITIES: A CASE STUDY OF SMALL FIRMS IN THE UK AUDIO VISUAL SECTOR
}

\author{
Keith RANDLE \\ Mariana DODOUROVA \\ University of Hertfordshire, UK
}

\begin{abstract}
The Creative Industries1 are acknowledged as a significant actual and potential wealth generator (Delors, 1993). However, compared with industrial manufacturing, finance or services there has been relatively little research on them, especially from an organisational point of view (Scase and Davi,s 2000). This paper presents the findings of an empirical study of the impact of digital technologies on small firms in the audiovisual sub sector of the creative media industries in the Eastern Region of the UK. The study contributes to our knowledge of the sector through examining how digital technologies are changing the way skills are acquired in an industry where individuals mainly "learn by doing" (Gregulis, 2010).
\end{abstract}

The findings demonstrate generally positive associations with digital technologies. Yet, the latter are also perceived by owner managers as a threat eradicating the market entry barriers of high cost equipment and highly developed occupational skills. Perhaps paradoxically, the study also identifies a very significant skills shortage in the SMEs operating in the Film and Digital Media industry. The study highlights the problems related to the acquisition of skills in small firms, during periods of rapid technological change and the contrasting processes of de-skilling and multi-skilling.

Keywords: Dynamic Capabilities, Digital Technologies

\section{INTRODUCTION}

At both a national and regional level, the creative industries are increasingly recognised for their existing and potential contribution to GNP and have been described as 'at the leading edge of the movement towards the information age' (Scase and Davis, 2000).

\section{The East of England Region}

The East of England is acknowledged internationally as a centre of excellence in the creative industries, specifically in film, television, animation, interactive media, design (graphic, packaging, product and multimedia design), and in the production of corporate video presentations and commercials. The region has one of the most highly qualified labour markets in the UK and is one of the main centres of the wider creative industries in the UK (City University/DTZ Pieda, 2002). There are three main concentrations of firms working in these areas: around West Hertfordshire (film), Norwich (TV and animation) and Cambridge (ICT and interactive media). Employing some 145,000 people in total, the creative clusters around West Hertfordshire and Cambridge are significant wealth generators for the East of England Region and account for one-tenth of the UK's total creative and media exports, by value (Screen East 2002).

West Hertfordshire provides the location of a number of important studios, the county is home to six commercial studios, and film has been the fastest growing of the creative industries. Almost $50 \%$ of all UK commercial studio production facilities are based in the Region and filmmaking traditions go back to the early part of the twentieth century. It has been estimated that around 125 companies are involved in film, television production, animation and new media production (Screen East 2002). 
Independent television production has developed around the Regional broadcaster, Anglia Television in Norwich. Animation forms an emerging sector in Norfolk ranging from the more basic animation required for children's television through to the production of state of the art avatars (Screen East 2002, Appendix 3) Around Cambridge is a computer development and interactive software cluster, a centre of excellence producing intellectual property and patents which already contribute to the next generation of content rich products and services for media producers and consumers.

While acknowledging film, television and the interactive software industries in the UK as growth sectors with $5.8 \%$ of the national workforce actively employed in occupations related to film, television, radio and video (ONS, 2001), it is also important to acknowledge that creative industries are not so significant in overall employment terms (except where ICT is concerned) as to figure amongst the DTI's ten recognised industrial clusters in the Eastern Region (DTI, 2001). Overall growth in employment also shields significant variations by sector. The DTI reports that there is a 'small local concentration of the film industry in Hertfordshire' which is actually an extension of the London (Soho) film industry (2001:7). However, the region is significantly underrepresented in ecommerce, television and film and video production. Nevertheless, it has been suggested that employment growth fails to reflect the very significant increases in output growth in these industries, up to $16 \%$ in 1998 (UKFC 2003).

In terms of national employment patterns, re-regulation and liberal market reforms during the 1980s, combined with new technologies, restructuring and incentives to self-employment and small business formation, led to a high degree of industrial fragmentation and growth in freelance working, self-employment, partnerships and other owner-managed enterprises (Baines 1999, Pratt 1977, Scase 1995), and away from employment in cultural and media related occupations in the UK. In 2005, of those working in independent production for television $61 \%$ were freelance or self employed (Skillset 2005a) and of those in film production 63\% were on fixed term contracts (Skillset 2005b). $51 \%$ of those working in television production worked in more than one sector (Skillset 2005a) generally this means independent film, video or commercials where skills are more interchangeable.

The Eastern Region reflects this national picture, characterised by a small number of large employers and a large and growing number of small businesses and freelance workers who cluster together on an opportunistic project-by-project basis, giving rise to an 'hourglass shaped' industry (Deuze 2007). The average size of Creative Media firms in the Region is below the UK average with most being small or micro businesses - the majority of companies employing six or less persons (Screen East 2002) and consisting of an average of four. Around 60\% of the workforce is estimated to be freelance or sole traders, reflecting Skillset's national figures.

The sector then can be characterised as fragile and fragmented, comprised largely of small independent production companies which operate as cottage industries. The particular characteristics of firms in the film sector create a unique set of problems for, amongst others, regional development and support agencies with the fragmented nature of the sector often making intervention strategies by providers difficult to execute. Long-term survival of these businesses is a key issue for the film and digital media industry, with business failure common.

\section{Training In the Creative Media Industries}

The most common route for new entrants onto the UK creative media labour market is by a 'Beckerian, learning-by-doing process where skills are picked up informally and without certification' (Baumann 2002:31) and where 'assistantships' rather than formally structured apprenticeships represented the route into the industry of nearly half of entrants (Dex et al, 1999).

Nevertheless the sector has an undeniably highly qualified workforce. According to Skillset a quarter of the audio visual workforce in the UK holds a media degree, with $66 \%$ of the industry being educated to graduate level. This compares with $16 \%$ of the UK workforce as a whole and is particularly evident amongst the younger members of the workforce, suggesting a continuing upward trend. However, a report examining the transition from college to work by film and audio visual media graduates in London (Holgate 2006) suggests that graduates themselves are frequently critical of the lack of practical training in the courses they have followed and this accords with the views of some employers interviewed during the present study. 
The Skillset Workforce Survey (2003) found an overall lack of training in the creative industries, particularly amongst freelancers. The difference between freelancers and employees in regard to access to training was significant, with only $44 \%$ of freelancers receiving training compared to $60 \%$ of employees. $94 \%$ of freelancers who sought training experienced barriers to receiving it, such as the fear of losing work or earnings, lack of information and high course fees.

However, there have also been voices arguing the case for autodidacticism in the industry, where the technology has become less costly, lighter and easier to use and the opportunities to use, for example in the internet, to learn filmmaking skills have increased considerably. Film Director Anthony Minghella, comments that as a result of digital technologies "...the means of production are going to be surrendered to almost anybody out there." (The Guardian, 2005: 9) suggesting a democratisation of the practice of film making with increasing numbers having access to the means of making films and presumably the skills required to do so.

\section{The Impact of Digital Technologies}

The speed of technological change in general and digitalization in particular in media industries during the last two decades has been overwhelming, with new enabling technologies being introduced not over decades but within months. Digitalisation has been defined as the process underlying the so-called multi-media revolution whereby digital technologies are gradually replacing earlier mechanical technologies (Von Tunzelman, 1995). Digital technologies are now having an impact upon every stage in the motion picture

value chain from script development through to production, post-production, distribution and exhibition. Technologies in the pre-production, production and post-production stages of filmmaking have developed rapidly in recent years, with the use of Digital Video now common and nonlinear PC based editing almost universal. The technology exists to shoot, edit, distribute and exhibit a movie entirely digitally (Culkin, et al 2003).

Digital technologies have been readily embraced for their versatility and cost efficiency. The accessibility and affordability of digital film and editing equipment has created an environment where clients and consumers can themselves now purchase high standard prosumer (professional/ consumer) camera equipment, shoot \& edit film using standard PCs and software and achieve reasonably professional results. The decrease in the prices for professional equipment makes the current situation, where access to significant capital is no

longer a barrier to entry, evident. Costs have fallen from $£ 103,000$ per digital editing suite (hardware and software) in 1994 (Screen Digest, 2003) to around £3000 in 2004.

Moreover, the growth explosion of the creative industries sector might be explained, at least in part, the dramatic increase in work productivity under the influence of digital technologies, which in turn has led to the development of new spheres of consumption, both in knowledgerelated and leisure activities.

However, studies have also suggested that the impact of digital technologies on the creative industries sector has been mixed. It has been argued that the rapid introduction of new digital technologies has transformed media markets into moving targets where firms are likely to be faced with increasingly dynamic competition. This situation poses vital questions concerning the set of skills and capabilities that can enable firms to adapt and compete successfully in the new context. Baumann (2002) comments that observers have speculated on how the labour market will supply the workforce needed for the continuing growth of the visual media - and

in particular TV - industries, with Sparks (1989) and Varlaam et al (1990) forecasting a dramatic future shortage of skilled employees for these industries. Indeed, in the particular context of the creative industries in the East of England, the retention of graduates and the attraction of new graduates from elsewhere are two key challenges faced by the sector despite, or perhaps even exacerbated by, its close proximity to London.

Moreover, there is also an argument that the convergence of digital content production has blurred traditional job profiles and consequently led to the multi-skilling of individuals (Cottle and Ashton 1999). While access to training suppliers and the quality of training are key issues in the creative 
industries generally (City University/Pieda Consulting 2002), these become even more significant when the speed of technological change is rapid, as with the adoption of digital technology by the modern film industry. A recent study on the implications of new technology for the skill and training needs of small to medium sized printing firms

(Smallbone et al 2000) showed that small firm survival ultimately depends on a systematic and structured approach to training.

Shooting a film using analogue techniques has traditionally been constrained by two factors; technical/professional know-how and the economic limits of the budget. Both of these constraints are directly related to shooting with film stock. Geuens (2002) characterizes traditional filmmaking as a time consuming and expensive process that requires a high level of professionalism and concentration from every person involved, with the crew being constantly confronted by obstacles which they learn to overcome through meticulous preparation, followed by the continuous exercise of exacting craftsmanship. He goes on to argue that digital filmmaking is eradicating these constraints which effectively maintained the quality of the product. The low cost of digital capture has lead to a less professional and focussed approach characterised by greater experimentation and an attitude to problem solving on set which can perhaps be epitomised by the expression 'we'll sort it out in post'. This suggests that the ability to manipulate the final image using digital technologies is so great that the shortcomings of what is shot on set in principal photography do not now form a major constraint on the quality of the finished product. Films can consequently be made by what this author (Geuens 2002) regards as second rate personnel and through a trial and error approach. He sees a radical discontinuity where digital represents a disruptive technology which will revolutionise the industry.

There is a counter argument to this which can be summarised as: by making learning loops faster digital video offers a higher degree of flexibility and freedom to creative talent and improvisation therefore does not lead to a lower quality product but to greater innovation and a more creative solution.

A further argument is that the 'digital revolution' is really a 'digital evolution' with technical challenges still ensuring that digital filmmaking has some way to go before it can achieve the aesthetic quality of analogue film. However, products other than feature film may benefit from technological change at an early stage while the production values expected of mainstream cinema require considerable maturity in the technologies employed. The independent production sector, then, may be less immune to the pressures associated with

technological change. While this could be characterized as 'dramatic' rather than 'radical' there appears to be agreement that 'profound changes in jobs and labour relations in the content industries are coming one way or another' (Ducatel, Burgelman and Bogdanowicz 2000: 516). This is likely to impact on both small firms and the majors.

The routines that shape labour relations in filmmaking are unlikely to change or be substituted by new technologies over night. Rather, technology will be adapted in a way that is consistent with existing structures and domains of power and expertise. As the literature on routines (Nelson and Winter 1982; Andersen 2003) and temporary organisation (Grabher 2004) suggests, routines are 'selfish' and replicate themselves beyond organisations, with process knowledge in project based industries such as the audiovisual industry, being remembered in networks. A change in technology is adopted along the existing skill base in these networks, in a path dependent way.

However while a 'business as usual' position may be applicable to the case of the major film studios, producing multi-million dollar feature films the realities of the UK regional film production/postproduction sector are somewhat different. In the regional context work on feature films represents only a small proportion of the work carried out by companies and the threat to livelihoods is more apparent and more immediate.

Hence the question that arises and, to the best of our knowledge, has not been addressed by previous studies, is what is the impact of rapidly changing digital technologies on fragmented industries dominated by small and micro enterprises such as the creative industries in the East of England?

Answering this question will contribute to both academic debate and industry knowledge througf 
advancing our understanding of the implications of digitalization. The findings can be deployed to develop comprehensive guidance to skill and capability development for industry practitioners and education and training providers. Moreover, they will provide regional development and support agencies with valuable insights into the problems and issues pertaining to the development of skills and capabilities by small enterprises in this highly potent sector.

\section{LINKING DYNAMIC CAPABILITIES AND DIGITAL TECHNOLOGIES}

Using the dynamic capabilities view as an underlying theoretical framework, our study examines the impact of digital technologies on small firms in the creative industries sector with particular emphasis on their ability to adapt to the new context through developing and deploying new competencies. Teece and Pisano (1994) introduced a 'dynamic capabilities' approach to strategy, which underlines the importance of dynamic change and learning. The development of this framework flows from a recognition that strategic theory is replete with analyses of firm-level strategies for sustaining and safeguarding extant competitive advantage but has performed less well with respect to assisting the understanding of how and why some firms succeed in building competitive advantage in regimes of rapid environmental change while others do not. Teece et al (1997:516) define dynamic capabilities as the firm's ability to 'integrate, build, and reconfigure internal and external competencies to address rapidly changing environments'.

The dynamic capabilities approach is especially relevant in a Schumpeterian world of innovationbased competition and 'creative destruction' of existing competences. It emphasizes two aspects: the shifting character of the environment, and the key role of strategic management in appropriately adapting, integrating and re-configuring internal and external resources and towards the changing environment (Teece and Pisano, 1994). Thus the primary focus of this approach is on the mechanisms by which firms identify, accumulate and deploy firm-specific skills and capabilities, and on the contextual factors that influence the rate and direction of this process.

The occurrence of technological change often requires redeployment of resources to develop capabilities suitable for the new technological regime (Tushman and Anderson, 1986). Teece (1988) argues that capabilities are sets of differentiated technological skills, complementary assets, and organizational routines and capacities that provide the basis for a firm's competitive capacities in a particular business. In essence, capability is a measure of a firm's ability to solve both technical and organizational problems. Capabilities typically have both organizational/economic and technical dimensions. The organizational/ economic dimension involves (1) allocative capabilities - deciding what to produce and how to price it; (2) transactional capabilities - deciding whether to make or buy, and whether to do so alone or in a partnership; and (3) administrative capabilities - how to design organizational structures and policies to enable efficient performance. The technical dimension, on the other hand, concerns the ability to learn, to develop and design new products and processes, and to operate facilities effectively. The competitive strength of a particular company is a function of its underlying technical and organizational capabilities while idiosyncrasies in

these capabilities trigger and sustain interfirm performance differences (Eisenhardt and Martin, 2000).

Prior research has reported the positive effect of dynamic capability development on small firms' survival and performance. Strategic initiatives which guide learning efforts towards development of new capability sets or rejuvenation of existing capabilities can help small firms quickly improve their performance or adapt to external trends more swiftly and nurture the emergence of internal creativity more effectively despite their lack of experience and/or resource constrains (Branzei and Vertinsky, 2006).

Hence human capital strategies can stimulate the emergence of novel capabilities through expanding external knowledge searches and facilitating the acquisition of innovative ideas from external sources, and through fostering ingenious knowledge cross-pollination within the firm. The initial development of new capabilities depends to a great extent on the quality of human capital, e.g. knowledge, interaction, task-ability, and willingness to learn. Hiring, training, improved 
coordination and learning-by-doing facilitate capability development (Leventhal and Myatt, 1994). Firms, which attract highly educated and/or highly skilled workers, provide skill-development and cross-training, and offer continued learning-by-doing and on-the-job training, develop 'difficult to trade and imitate, scarce, appropriable and specialized' human capital (Amit and Shoemaker, 1993:36). Attracting and training high quality technical and scientific personnel is considered critical for growth and performance, particularly for firms in dynamic environments (Deeds, et al, 1999).

However, the intensity of the learning efforts in knowledge-intensive, complex or dynamic environments depend not only on the firm's requisite human capital but also on its operational routines. Periodic inflows of qualified personnel and specialized training can improve firms' capabilities by effectively spanning different knowledge bases (Boland et al, 2001). Several studies have associated creative cross-pollination of skills across different areas of expertise with the effective recombination of technological, marketing, and organizational know-how (Helfat and Peteraf, 2003) conditional upon the quality and energy of firms' professional personnel (Deeds et al, 1999).

Hence sustained capability development requires firms to continuously nurture novel operational routines by questioning, reshuffling, realigning, and rejuvenating their core skills. Companies are increasingly organizing their activities less around functions and operations and more around timedesignated projects where temporary cross-functional teams are assigned to specific projects with a clearly defined outcomes and completion dates. This type of project-based organization is increasingly viewed as a model achieving innovation, adaptability and rapid learning.

The equivalent of this model in small firms is the assembly of a group of skilled workers who can be used as 'skill containers' and easily employed in different markets (Kristensen, 1995) Firms are not strictly committed to any one business or value proposition, but instead aim strive to keep these skilled employees busy and find more valuable uses for their skills hence expanding the competency base (Cole, 2004) and generating value from extant endowments.

However, although multi-skilling seems to be a necessary condition for the adaptation and growth of smaller companies, there is also a downside. As Avilés et al (2004) have pointed out, working in several fields of competencies may increase the scope and productivity of a firm, but often leads to a lack of training and professionalism in core tasks. This issue needs to be clarified for its vital importance to small firms, particularly in the context of rapid introduction of new digital technologies and the related questions concerning the development and rejuvenation of skills and capabilities.

Managerial decisions are acknowledged as some of the most critical antecedents of capability transformation (e.g. Adner and Helfat, 2003), influencing the depth of understanding of the external environment, the speed of reaction and the specific actions taken in response. Recent theoretical studies conceptualize managerial decisions and strategic choices as essential stepping stones in the capability-building process (Helfat and Peteraf, 2003, Zahra and George, 2002, Eisenhardt and Martin, 2000). Appropriate strategic choices may help firms overcome the constraints of their existing resource endowments by guiding the further advancement of existing skills and by facilitating development of new capabilities. Managers can shape a firm's competitive posture by specifying the content, sources of desired competencies and their intended effect (Bierly and Chakrabarti, 1996). Yet, the question of whether or how small firms deploy strategic interventions to enhance their existing capabilities and/or develop new ones has remained largely neglected by prior research.

\section{RESEARCH METHOD}

The data reported in this paper came from the results of an empirical study which involved telephone interviews with thirty production and post-production companies to investigate the impact and implications of digital technology at a UK Regional level. A qualitative methodology was employed to fully explore the level of understanding and depth of feelings that respondents had about the impact and implications of digital technology. Thirty telephone interviews, of thirty-minute duration, were conducted in the course of one month, with local business decision makers (predominantly 
owner managers) and individuals working in the film industry. Organisations were chosen randomly and approached for co-operation with the aim of getting access to a spread of audio visual sector companies covering both the production and post-production stages and of carrying out a total of thirty interviews. Following the taped interviews a thematic analysis was carried out.

Research was conducted amongst organisations working within the film and audio visual industry in the counties of Hertfordshire, Cambridgeshire, Essex, Suffolk \& Norfolk. The principle business activity of the organisations interviewed was television, film and commercial and corporate video production. A minority of companies were solely engaged in advertising and maintaining an internet library. 25 of the interviews were with individuals in production organisations and five in postproduction, although in practice the distinction was nebulous with many working across this boundary. This in itself is in part a function of digital technologies which have allowed the boundaries to become blurred.

The vast majority of organisations interviewed were relatively small, both in terms of the number of employees and their level of turnover. Most companies had fewer than five full time employees, although many of them supplemented this by contracting Freelance staff, as and when the dictates of a project demanded.

The majority of organisations operated from a single office. All relied heavily upon email and mobile phone services, but few had any permanent remote working practices or computer networks in place. Most organisations operated on a turnover of $£ 100,000$ or less. There were a few notable exceptions to this, where the research spoke to relatively small film units that were part of much bigger corporations. Consequently these types of organisations, with access to more comprehensive budgets and resources provided an interesting contrast to the remainder of the sample frame.

Approximately half of all organisations surveyed were well-established businesses that had been in operation for ten years or more. The majority had been formed by individuals who had 'learnt their trade' within the industry before setting up their own business. These individuals were typically highly experienced in their field of expertise and had been using analogue equipment prior to the advent and advancement of digital equipment.

A generic topic guide was devised to facilitate discussion around key areas of the respondent's organisational profile, perceptions of the impact of digital technology within the wider film industry, the impact within their own organisation, security, standards and training \& recruitment. However, the nature of each individual's experiences, attitudes and general level of engagement with digital technology ensured that respondents themselves firmly shaped the agenda for the discussions. The research was conducted under the Market Research Society Code of Conduct, and consequently no reference will be made to any individuals within this analysis.

\section{FINDINGS}

In the section which follows we present the findings from our empirical research. While the interviews ranged over a number of issues of concern to owner managers and decision makers in the small firms we selected, we have chosen here to focus here on those related to the connected issues of training, skills and technological change.

The Managing Director of a Postproduction company in our survey described how:

'When I was a little boy, I would go and work in a film studios or become a runner and that is how you learnt the industry, you worked your way through each grade...

But he continued:

'.....Now there aren't the companies that can afford to do that anymore and take on a boy that doesn't know anything and train them up. The companies need profits and they need someone 
who can do the job........ there is no going into a company and making cups of tea and things like that...'

Consequently, it is being argued that the traditional 'Beckerian' method of developing skills in the industry is not longer sustainable. Small firms were looking for individuals who already possessed the necessary skills to contribute towards the business.

Nevertheless, few of our respondents were found to be actively seeking out and attending training courses of any description in digital technology, preferring to learn about equipment and techniques 'hands-on' and on the job. For many of the smaller businesses time away from their work, plus the associated costs of attending courses did not make it a viable option. Consequently, training normally provided by large companies and almost always outsourced by smaller enterprises, is compromised.

There was some concern amongst respondents regarding the media studies courses offered by Further and Higher Education institutions. Whilst most felt that these courses provided a reasonably sound theoretical foundation, there was insufficient practical experience being gained by students. New entrants to the film industry required a considerable amount of hands-on practical training:

'What happens is Universities and colleges offer what they call 'Media Studies' which is not a practical ' how the industry works'. ...... training in the industry at the moment is very bad.. ...or it is very costly.'

(Managing Director, Postproduction Company)

'I'm very cynical about media studies I'm afraid and I'm probably not the only one......... suppose I'm old fashioned...... I went through college at a time when one went to do a degree in a traditional subject and then went on and trained to become a producer or whatever afterwards and I don't think there was a lot wrong with that..... when academic institutes start running technical training courses it gets out of date so soon.. that I'd question its value'

(Partner, Production Company)

Virtually everyone interviewed during the study expressed concern that the emergence and growth of digital technology, especially DV, was leading to a belief that 'anyone can make films'.

As two independent producers reported, competition was increasing both as a result of new entrants to the business and clients taking 'make' rather than 'buy' decisions:

'...it's exactly what's happening in the video industry ...... there is a lot of competition from boys with their cameras in their bedroom sort of thing, and there is also competition in the sense that a company will say 'I'm not going to buy that, we're going to do it ourselves'.

(Partner, Production Company)

This respondent's comment reflects the ambivalent attitude of many of our interviewees to digital:

'...it draws more people into the industry because it is more accessible and that is a good thing. Ultimately it will probably put me out of business. If you have an idea now you can go out and realize it...'

(Editor, Postproduction company)

The higher 'knowledge intensity' of digital cameras requires less training and seems therefore more easily accessible. However a producer maintained that:

'....it's not just a question of pressing buttons ..... that gets overlooked, so it's quite difficult to quantify that kind of expertise and people are reluctant to pay....'

This suggests that clients believe that the costs the production company has to meet, in terms of outlay on equipment and expertise are falling with the introduction of cheaper and easier to use technology. The client expects this perceived fall in costs to be passed onto him, the customer. Consequently as, for instance, the differences between cameras priced at $£ 60,000$ and those at $£ 60 €$ 
become more subtle, prices for the equipment in use no longer have such explicit quality signalling characteristics, making clients more wary when spending money on services from companies in the industry.

Findings from the interviews also suggest that while digital technology has made it easier to enter the market, it has become far more difficult to remain in it. As technology advances quickly, firms are forced into a potentially costly continuous upgrade spiral:

'.... there is this constant drive to update, constant drive to change .... Now you buy something and you're not really sure how long it's going to last and if you get three years out of it then that's good going. So it's difficult, the longer term financial, capital equipment and financial strategy is very different'

(Partner, corporate video production company)

Not only are some of the cost savings through digital technology offset by upgrading costs, as mentioned earlier they also have to be passed on to clients as competition grows more fierce. It is therefore unsurprising that the enthusiasm for digital in smaller companies has waned:

'....They say that all this technology was actually supposed to make people's lives easier but in fact it just means that you press their nose that much harder to the grindstone'

(Partner, corporate video production company)

The situation of the audiovisual industry in the Eastern Region appears therefore as a paradox. On the one hand academic commentators and government training agencies warn of skill shortages, while practitioners complain about the opposite: that digital technology requires less skill and therefore reduces market entry barriers so potentially threatening livelihoods.

There does appear to be evidence for this in the case of small firms, as is illustrated by the statement of a young independent television producer:

'...It depends what we've got going on. I could be filming. I could be editing. I could be just putting together the administration for any of those two elements of the process. I could be a sales executive one day. I could be a presenter the other day because I have to, because of where we are. We're growing. It's all sort of multi skilled so I wear many different hats...'

(Producer, Independent television production company)

This tendency towards a blurring of the boundaries between formerly distinct sub-sectors was reflected in our firm sample. While the research was oriented towards the production sector in many cases firms worked in both production and post-production.

In summary, while the audio visual workforce is highly qualified many of its skills are acquired on the job. Graduates of media related courses do not rate them particularly highly in terms of the equipping them with the practical skills that they need in employment. Small firms tend to expect their employees to come ready equipped with skills rather than have to provide them with training but freelancers, in particular, find it difficult to get access to training for a range of reasons. When technologies are changing quickly it becomes even more important that firms have access to appropriate skills, but these skills are not necessarily related to the changing technologies and may include, for example, business awareness related and personal skills.

\section{DISCUSSION AND CONCLUSIONS}

The research carried out among the sample of production and post-production companies in the Eastern Region showed that on the whole the adoption of digital technology was viewed as a positive step for businesses. It brought with it improvements in production times, reductions in costs for equipment purchase and hire, greater flexibility in working practices and higher productivity. However, a number of significant threats to the future shape of the local industry emerged. These concerned the linked issues of training, deskilling and product quality. Falling barriers to entry are 
likely to encourage competition and attract new entrants into a sector that is already made up almost entirely of micro and small business firms.

Our findings are supported by those reported in other academic literature and suggested in the reports of regional support agencies, namely that there is a need for the continuous updating of courses of media related training and education to keep pace with new technological developments. This in itself raises the question of the adequacy of educational funding required to resource high tech audio visual equipment. However, it is also the case that there is a need to ensure that at both initial graduate entry level and later CPD training should include business awareness training as well as technological updating. As the hourglass shape of the sector develops those owning, managing or working for small firms need to be multiskilled rather than simply technical specialists.

Findings from the research also have implications for the services to small firms from regional support agencies. Firstly, small firms need to extend their thinking beyond products and services to business models and strategic innovation. Consistent with previous research (e.g. Smallbone et al, 2000), this study suggests that the dominant role of the owner/manager of a small firm can lead to a narrow strategic perspective. This is particularly apparent where owner/managers lack formal training or qualifications. Strategic deficiencies are of a major disadvantage in rapidly changing environments. A related problem appears to be the narrow

focus of many small firms on their customers, making their development dependent on them. Frequently this is reinforced by neglect of systematic search activities concerning new market opportunities.

Small firms are less capable of searching for and using codified knowledge which makes them more reliant on personal ways of transferring this knowledge and on learning-by-doing and interacting. Moreover, it is also more difficult for them to apply formal contracts, relying more on trust-based, informal relations instead. Hence small firms need to be made aware of the importance of networking and how it can contribute to their performance and dynamic adaptation through exchange of tacit knowledge, potential collaborative relationships and the mobility of the workforce.

More importantly, as business environments become more complex and turbulent, and less predictable, companies must build multiple capabilities and achieve excellence across multiple performance dimensions. Capabilities need to be developed not only along technical dimensions but also along organizational dimensions Teece, 1988). Indeed, the latest trends in the field of strategic management suggest that clusters (networks) of small firms working on a project-by-project basis provide the perfect flexible setting for innovating in such business environment.

However, activities directed toward deploying the existing stock of knowledge (exploitation), e.g. purchasing, producing, selling, distributing, finance, typically require high levels of specialization and coordination through rules and routines. This research demonstrates that support for small firms is needed in those organizational, more 'mechanical' areas, in the form of innovation and technology finance, training in planning, financing, and marketing, and development of downstream (distribution) relationships.

Consistent with previous research among the film and media business community (as well as amongst the creative industries more generally), secondary research underpinning our study has revealed that the key need for the creative industries is not creative or technical (apart from ICT) skills but business, management and organisational skills. The gaps identified include marketing, finance and bookkeeping, strategic planning, pricing, general ICT, and self-presentation. These skills gaps are particularly acute amongst the smallest businesses and the self-employed or freelancers. More generally new entrants need work awareness skills

(working in a team, working to commercial deadlines, handling customers, grasping market potential) and an understanding of the importance of networking. Freelancers need career building skills and small businesses need marketing support to encourage learning, development, marketbuilding and collaboration (East of England Cultural Skills and Learning Group 2003, East of England Creative Industries: Advice and Analysis, EEDA, 2002). 
There appears to be a general shift in the way skills are being acquired in the audiovisual industry. The readily accessible nature of digital equipment reduces initial learning costs, but the tendency of this equipment to become outdated quickly raises the necessity to constantly adapt the associated skills to changes in technology. Thus learning cycles have become shorter but also more frequent.

While this paper has contributed towards our knowledge of the implications of rapidly changing digital technologies on small firms in the audio visual industries, it begs a number of questions which future research might focus upon. For example:

What strategic and organisational characteristics trigger interfirm performance differences in creative industries?

How should training courses be improved/modified to deliver more value in the context of digitalization?

To what extent are our findings applicable to small firms in other industries, and particularly in sectors where digitalization has induced extensive structural changes, e.g. telecommunications and computer software?

What level of state intervention is needed to support creative clusters and small firms in such industries?

The latter question is complicated by the heterogeneity of small firms in terms of technological level, market relations and competitive strategies among others, which makes it very difficult to target support in a way that matches the specific problems and needs of very different firms. 


\section{REFERENCES}

Adner, R. and Helfat, C. (2003) 'Corporate Effects and Dynamic Managerial Capabilities' Strategic Management Journal, 24 (10), 1011-1025

Amit, R. and Shoemaker, P.J.H. (1993) 'Strategic Assets and Organizational Rent' Strategic Management Journal, 14 (1), 33-46

Anderson, P.H. (2003) 'The Embeddedness of Selfish Routines: How Routines are replicated in Business Networks', Industry and Innovation 10(2) 159-177

Asheim, B.T. (2002) 'Temporary organisations and spatial embeddedness of learning and knowledge creation' Geografiska Annaler 84 B (2) 111-124

Garcia Avilés, J.A., Harrison, J., Leon, B. and Sanders, K. (2004) Journalists at Digital Television Newsrooms in Britain and Spain: workflow and multi-skilling in a competitive environment. Journalism Studies, 5(1), 87-100

Baines, S. (1999) 'Servicing the media: freelancing, teleworking and 'enterprising' careers' New Technology, Work and Employment, 14(1), 18-31

Baumann, A. (2002) 'Informal labour market governance: the case of the British and German media production industries', Work, Employment and Society, 16(1), 27-46

Bierly, P. and Chakrabati, A.K. (1996) 'Generic Knowledge Strategies in the US Pharmaceutical Industry’, Strategic Management Journal, 17, 123-135, (Winter Special Issue)

Boland, R.J., Singh, J., Salipante, P., Aram, J.D., Fay, S.Y., Kanawattanachai, P. (2001) 'Knowledge Representation and Knowledge Transfer', Academy Management Journal, 44 (2), 393-417

Branzei, O. and Vertinsky, I. (2006) 'Strategic Pathways to Product Innovation Capabilities in SMEs', Journal of Business Venturing, 21, 75-105

City University/DTZ Pieda (2002) City University/Pieda Consulting (2002) East of England Creative Industries: Advice and Analysis

Cole, A. (2004) 'Distant networking: the global sourcing of talent and the new geography of European animated film production' Copenhagen Business School [online] http://139.124.177.94/ proxim/viewpaper.php?id=298 [March 26, 2005]

Cottle, S. \& Ashton, M. (1999) 'From BBC Newsroom to BBC Newscentre: On Changing Technology and Journalist Practices' Convergence, 5(3) 22-43

Culkin. N., Randle, K. and Sychowski, P. (2003) Facing the Digital Future: The Implications of Digital Technology for the Film Industry, for EEDA (East of England Development Agency)

Deeds, D.L., DeCarolis, D., Coombs, J.E. (1999) 'Dynamic Capabilities and New Product Development in High Technology Ventures: An Empirical Analysis of New Biotechnology Firms', Journal of Business Venturing, 15, 211-229

Delors, J. (1993) White Paper, Growth, Competitiveness and Employment: The Challenges and Ways Forward into the 21st Century

Deuze, M. (2007) Media Work, Cambridge: Polity

Dex, S., Willis, J., Patterson, R. \& Willis, J. (1999) British Film Institute Television Tracking Study, 1994-1998 (computer file, SN 4015). Colchester: The Data Archive 
DTI (2001) Business Clusters in the UK - A First Assessment

DTI (2001) Business Clusters in the UK - A First Assessment Volume 2 Regional Annexes, Eastern p.7

Ducatel, K., Burgelman, J.C. \& Bogdanowicz M (2000) Scenario for Europe's Media Industry: employment trends and changing skills. Info, 2(5), October, 496-516

East of England Cultural Skills and Learning Group (2003) Development of a Skills Matrix for the Creative Industries, October

EEDA (2002) East of England Creative Industries: Advice and Analysis

Eisenhardt, K.M. and Martin, J.A. (2000) 'Dynamic Capabilities: What are they?' Strategic Management Journal, 21, 1105-1121

The Guardian G2 (2005) March 7th p9

Geuens, JP. (2002) The Digital World Picture. Film Quarterly, 55(4), 16-27

Gregulis, I. and Stoyanova, D. (2010) "'I Don't Know Where You Learn Them": Skills in Film and TV' in Creative Labour, A. McKinlay and C. Smith (eds) Basingstoke: Palgrave Macmillan

Grabher, (2004) Learning in Projects, Remembering in Networks? Communality, Sociality, and Connectivity in Project Ecologies. European Urban and Regional Studies 11(2), 103-123

Helfat, C.E. and Peteraf, M.A. (2003) 'The Dynamic Resource-Based View: Capability Life Cycles' Strategic Management Journal,24, 997-1010

Holgate, J. (2006) Making the transition from college to work: experiences of media, film and television students, and recent graduated in London's audio-visual industries. London: Working Lives Research Institute

Kristensen, P. H. (1995). On the Constitution of economic actors in Denmark: Interacting skill containers and project coordinators in Whitley, R. \& Kristensen, P. H. (eds.). The changing European Firm: Limits to Convergence. London \& New York: Routledge.

Leventhal, D. and Myatt, J. (1994) 'Co-evolution of Capabilities and Industry: The Evolution of Mutual Fund Processing', Strategic Management Journal, 15, 45-62

Nelson, R., R. and Winter, S. (1982) An Evolutionary Theory of Economics Change, Harvard University Press

Magid, R. (1999) Master of His Universe: George Lucas Discusses The Phantom Menace and the impact of Digital Filmmaking on the Industry's Future. American Cinematographer, 80(9) 26-35 September

ONS (2001): Labour Force Survey - Sub National Data Service, Winter

Pratt, A.C. (1997) 'The cultural industries production system: A case study of employment change in Britain, 1984-91', Environment and Planning A, 29(10), 1953-1975

Scase, R. (1995) 'Employment relations in small firms', in P.Edwards (ed.) Industrial Relations: Theory and Practice in Britain, Blackwell, Oxford, 560-595

Scase, R. and Davis, H. (2000) Managing Creativity, Buckingham: Open University Press Screen Digest (2003) Digital Cinema Business Models: The Global Outlook London: Screen Digest Ltd, May 
Screen East (2002) Screen East Business Plan 2003/04 Appendix 3: An Economic Summary of Film and the Audiovisual Sector in the East of England

Skillset (2003) Skillset Workforce Survey, London Skillset

Skillset (2005a) Survey of the Audio Visual Industries' Workforce 2005, London Skillset

Skillset (2005b) Film Production Workforce Survey, London, Skillset Smallbone, D. et al (2000)

"The implications of new technology for the skill and training needs of small-and medium-sized printing firms", Education and Training, 42 (4/5), 299-307

Sparks, C. (1989) The impact of Technological and Political Change on the Labour Force in British Television. Screen, 30 (1), 24-38

Teece, D.J. (1988) 'Technological change and the nature of the firm', in Dosi, G., Freeman, C., Nelson, R., Silverberg, G., Soete, L. (Eds.), Technical Change and Economic Theory, Frances Pinter, London

Teece D.J., Pisano, G. and Shuen, A. (1997) 'Dynamic capabilities and strategic management', Strategic Management Journal, 18(7), 509-533

Teece, D. and Pisano, G. (1994) 'The dynamic capabilities of the firms: an introduction', Industrial and Corporate Change, 3, 537-556

Tushman, M. and Anderson, P. (1986) 'Technological Discontinuities and Organizational Environments', Administrative Science Quarterly, 31, pp. 439-65

UK Filmcouncil, (2004)

Varlaam, C., Leighton, P., Pearson R and Blum, S. (1990) Skill Search: Television, film and video industry employment patterns and training needs, Brighton: Institute of Manpower Studies

Von Tunzelman, G.N. (1995) 'Localised Technological Search and Multi-technology Companies', Mimeo, SPRU

Zahra, S.A. and George, G. (2002) 'Absorptive Capacity: A Review, Reconceptualization, and Extension’, Academy Management Review, 27 (2), 185-203 